\title{
INTRODUCTION: The contemporary challenges facing plurilingual societies
}

Edition 7, 2021

Associate Professor Michael Ewing

DOI: $10.37839 / M A R 2652-550 X 7.8$

A twentieth century ideal imagined that promoting a common language within a nation, or even around the world, could bring about greater cooperation and understanding.

But we see time and again that the power structures needed to create, propagate and enforce common systems of communication can simultaneously disadvantage segments of society, especially those who are already marginalised. In addition, unifying languages often participate in and reinforce social and political structures that can easily quash plurality of thought, expression and identity.

All societies are fundamentally plurilingual. Accepting and working with this fact is more productive than ignoring or trying to suppress linguistic plurality; and in the long run it can have a transformative effect on both societies and individuals.

The term plurilingual is often used in educational contexts, but it is also useful for thinking about the interface between education and society, and about society more widely. It is also a more flexible term than, say, multilingual, which can imply many discrete languages used separately on different occasions or by different people. Plurilingual suggests a plurality of languages and a plurality of complex ways in which communities, institutions and individuals engage in using languages. This does not necessarily mean that everyone should speak multiple languages, but rather that no one should be prevented from having access their language(s) of 
choice. Crucially, language diversity-similar to cultural and environmental diversity-can strengthen society, making communities and individuals more agile and adaptable, diverse and inclusive.

Despite the advantages of embracing a plurality of languages and language experiences, powerful institutions, governments and ideologies (Joseph Lo Bianco) often assume or promulgate a monolingual ideal, thus producing significant challenges to those working to nurture plurilingual societies. But the power of institutions, governments and ideologies can also be used to support multiple languages and ways that individuals and societies engage with languages.

Australia is emblematic of these tensions and opportunities. Despite it being home to speakers of hundreds of different languages-indigenous and migrant-a largely monolingual and Anglocentric perspective, whether conscious or not, continues to pervade some levels of society, particularly the powerful and elite, affecting attitudes towards multilingualism and language learning. This view is further buttressed by the current dominance of English in global communication.

Given Australia's geographic location and the importance of our connections to Asia, which have been highlighted by successive governments now for decades, countering Anglo-centric and Eurocentric biases are in the national interest. Despite this, there continue to be societal perceptions which discourage students for undertaking the study of languages (Carol Hayes et al.)

A monolingual mindset may only see value in other languages when they provide an instrumental or economic advantage. Yet studies have shown that engaged language learners often have what are called integrative motivations, in which interculturality itself is the goal, rather than possible economic reward (Jun Ohashi and Hiroko Ohashi). Economic benefits can flow from engaged language learning, but emphasis on purely instrumental motivations may in fact disengage students, thus leading to loss of the very economic benefits an instrumentalist approach is meant to foster.

The COVID-19 pandemic has underscored both the need for multi-language literacy 
and the difficulties of achieving it during pandemic-related restrictions on movement.

Grace Qi notes that student motivation is heightened by social interaction and complex interrelationships between communities and identities, especially in contexts where language proficiency has direct implications for the efficacy of health-related information. The actual teaching of languages becomes critical, especially when complex and developing situations require nuanced understanding. Yasuhisa Wataname discusses ways to promote student engagement through online teaching with activities designed to facilitate maximum student involvement; and Dwi Noverini Djenar writes that a one-to-one mindset (often conceived as Anglocentric) in moving between languages might be understood as a way to minimise misunderstanding but can produce simplifications and misinterpretations which cover up the complexities of cultural and political differences.

Translation is a particularly complex and inherently political part of cultural and political difference. Bei Hu points out the Chinese Communist Party-approved translation of its official rhetoric into English imposes cultural filters that remove possible violations of Chinese nationalist ideology. She argues that successful 'intercultural communication should not be monodirectional and top-down only', but must take into account the complex contexts it inhabits. Delia Lin considers the fraught context that is the teaching and learning of English in China, where the international hegemony of English and the perceived cultural biases that go with it are particularly acute. In the Middle East, important political considerations can be lost with 'received' translations. Heightened political awareness can be fostered with careful reconsideration of translation process. Yasir Sulieman demonstrates this in the case of the Palestinian-Israeli conflict, where mainstream translations can render inequalities and contested perspectives invisible.

A lingering legacy of nationalist movements and colonialism in much of the region, is a mindset which gives rise to hegemonic domination by a small set of languages. In the case of Pakistan, Urdu as the national language and English as an official 
language together pose a double threat to regional languages spoken throughout the country (Ameer Ali and Maya David). At the same time, tensions between proponents of Urdu and English expose an economic divide demonstrated by the much higher quality of English medium education favoured by elites compared to Urdu medium education available to the wider population (Hussain Qadri), with little opportunity for mother-tongue education by first-language speakers of regional languages.

Indigenous language speakers are among the most marginalised. Recent democratic reforms in Nepal are associated with indigenous rights and mother-tongue education, yet similar to Pakistan, the privileging of English by elites syphons resources from mother-tongue education among more marginalised groups, thus further exacerbating disadvantages (Prem Phyak). In Taiwan, as in many jurisdictions in the region, tensions between scales of language are manifest in policy which promotes a plurilingual society, but whose implementation often continues to be problematic (Brett Todd).

In all these examples, there are competing narratives and ideologies around the roles of indigenous, national and international languages. This is clearly exemplified by the Indonesian situation where great linguistic diversity across the archipelago is often in tension with the unifying force of the national language, Indonesian. Justin Wejak further reflects on Indonesia and the interconnectedness between language and identity particularly in plurilingual societies where it is not just about how one identifies oneself, but also how one is identified in relation to otherness.

The 'inequalities of multilingualism', often involve the devaluing of some languages and the valorisation others. Devalued languages are often indigenous but may also be heritage languages of immigrant communities or simply 'foreign' languages in general. Valorised languages may be regional linga francas, national (or nationalistic) languages or international languages such as English, Arabic or Chinese.

It may seem inconsistent to note inequalities of multilingualism while promoting the 
advantages of a plurilingual approach, yet this is precisely the point. The solution to inequalities of multilingualism is not to do away with opportunities to use, promote and study multiple languages in favour of a dominant language. Rather it is to create and develop equalities within plurilingual contexts, whether through engaged teaching and learning, culturally aware translation practice or support for the linguistic self-determination of more marginalised segments of society.

Image: Street market in Singapore. Credit: Brian Evans/Flickr.

An addition was made to this article after publication. 